\title{
Role of Kletik oil, Ginger and Garlic Extracts towards Soft Tissue Injury
}

\author{
Benjamin Yong Qing Nan, ${ }^{1}$ Yoyos Dias Ismiarto, ${ }^{2}$ Adhi Kristianto Sugianli ${ }^{3}$ \\ ${ }^{1}$ Faculty of Medicine Universitas Padjadjaran, ${ }^{2}$ Department of Orthopedic and Traumatology \\ Faculty of Medicine Universitas Padjadjaran/Dr. Hasan Sadikin General Hospital, Bandung, \\ ${ }^{3}$ Department of Clinical Pathology Faculty of Medicine Universitas Padjadjaran/Dr. Hasan Sadikin \\ General Hospital, Bandung
}

\begin{abstract}
Background: There is an increased consumption of herbal medicines throughout the world as an alternative treatment for curing health problems. Several herbal medicines are believed to contain anti-inflammatory properties that could trigger healing process. But little is known about the combination effect of herbal medicines. Therefore, the objective of the study was to determine the effects of garlic, ginger and coconut oil (kletik oil) on soft tissue injury (swelling).

Methods: The study was held in the research laboratory of Faculty of Medicine Universitas Padjadjaran, from 24th September until 1st October 2014. This experimental study used 7 healthy rabbits (Lepus curpaeums, $\pm 2.5 \mathrm{~kg}$ ) as animal models for each control and intervention group with induced soft tissue injury in the dorsal ear to mimic swelling (inflammation). The mixture of herbs was applied on the injured site in the trial group, while the healing process was denoted by the thickness of edema and time of observation. The data was analyzed using Wilcoxon test.

Results: The study results showed that after observation time of 0.5 hour, 2 hours, and 5 hours, edema thickness was unvaried. Onset of action of the herbal mixture began 24 hours after induced injury, with significant difference of edema thickness on both groups; hence the $p$-value $0.019(p<0.05)$.

Conclusions: The herbal mixture of ginger, garlic, and coconut oil (kletik oil) contains anti-inflammatory properties to enhance the healing process of soft tissue injury. [AMJ.2016;3(3):421-4]
\end{abstract}

Keywords: Ginger, herbal medicine, inflammation, kletik oil, soft tissue injury

\section{Introduction}

There is an increased consumption of herbal medicines throughout the world as an alternative treatment for curing health problems such as heart diseases, diabetes, high blood pressure and certain types of cancer. ${ }^{1}$ Herbs such as garlic, ginger and coconut oil (topical) are chosen because these herbs are able to alleviate and provides antiinflammatory effect towards cell injury. ${ }^{2-4}$

Furthermore, garlic (Allium sativum) contains a sulfur natural compound, allicin, a substance that have effect as antibacterial, antiviral and antifungal properties. ${ }^{5}$ Ginger (Zingiber officinale) has been used in traditional medicine for its therapeutic properties. According to the results in vitro studies, the rhizome of ginger contains gingerols, which inhibits synthesis of pro-inflammatory cytokines, IL-1, TNF- $\alpha$, IL-8, prostaglandin
(PG) and leukotriene (LT), and also inhibits the inducible enzyme cyclo-oxygenase-2 (COX2). ${ }^{6}$ Moreover, coconut (Cocos nucifera L), is capable of increasing antioxidant enzymes, reduces lipid peroxidation content and also has antithrombotic effect. It is reported that it also has anti-nociceptive and anti-inflammatory properties. $^{3}$

The skin is part of soft tissue composed of epidermis, and dermis. ${ }^{7}$ In acute soft tissue injury, sign and symptoms occur rapidly and occur from a known or unknown incident. ${ }^{8}$

In this study, it has never been proven that these three topical herbs mixture will provide an anti-inflammatory effect towards soft tissue injury. So from these three different types of herb, coconut oil will be used as a topical cream that is able to refine and moisturize skin conditions, whereas garlic will be added to act as emulsifier for the fat inside the coconut oil, with generation of heat to provide

Correspondence: Benjamin Yong Qing Nan, Faculty of Medicine, Universitas Padjadjaran, Jalan Raya BandungSumedang Km.21, Jatinangor, Sumedang, Indonesia, Phone: +6287822004705 Email: poornoob159@gmail.com 
optimal vasodilation, ginger is added. Due to their individual anti-inflammatory properties, when mixed together, these topical agents will have enhanced anti-inflammatory properties in treating soft tissue injuries. ${ }^{3,4,9,10}$

Therefore, the objective of the study was to determine the effects of garlic, ginger and coconut oil (kletik oil) on soft tissue injury (swelling).

\section{Methods}

The research was conducted from September until October 2014 at the research laboratory Faculty of Medicine, Universitas Padjadjaran. This study was an experimental study on 7 healthy rabbits (Lepus curpaeums $\pm 2.5 \mathrm{~kg}$ ). The herbal mixture was prepared from $15 \mathrm{ml}$ of coconut oil, $5 \mathrm{~g}$ of crushed garlic, $5 \mathrm{~g}$ of crushed ginger. Next, it was mixed together into a container, then stored in the refrigerator for 24 hours. In both two groups: the control and intervention group, the rabbits were induced soft tissue injury (edema) by using a soft tissue clamp onto the rabbit's ear to mimic injury of the human body. The injury's site (rabbit's ears) was left to undergo swelling (sign of inflammation). There were 6 consecutive periods to observe the swelling: 0.5 hours, 2 hours, 5 hours, 24 hours, 120 hours and 168 hours. On the intervention group, the topical herbal mixture of ginger, garlic and coconut oil was applied onto the animal models and left for the healing process observation. The reapplication of the herbal mixture was designated on each observation period. The healing process was identified and measured with a measuring caliper ( $\mathrm{mm}$ ) through the thickness of edema and time of observation (hours).

The result was expressed as mean $\pm \mathrm{SD}$ and was denoted by the thickness of edema caused by inflammation reaction. The groups were compared using the Wilcoxon statistical testing. The data collected will be plot into a graph. $^{11}$

During the observation time, all animal models were placed in a secure and hygienic animal rabbit cage where sustenance was provided. This study was approved by the Health Research Ethics Committee, Faculty of Medicine, Universitas Padjadjaran.

\section{Results}

The result of experiments on 7 rabbits during the 168 hours showed the comparison result between control group and intervention group based on the thickness of edema and time of observation. In both control and intervention group, it was found that during 0.5 hours up to 5 hours, there was no difference in the edema thickness, whereas, the differences only occured from 24 hours up to 168 hours; the biggest difference occurred on the 168 hours during observation time. The thickness of edema in the control group was higher $(0.134 \mathrm{~mm})$ than in the intervention group (0.121 mm) (Figure 1).

The observation time was compared

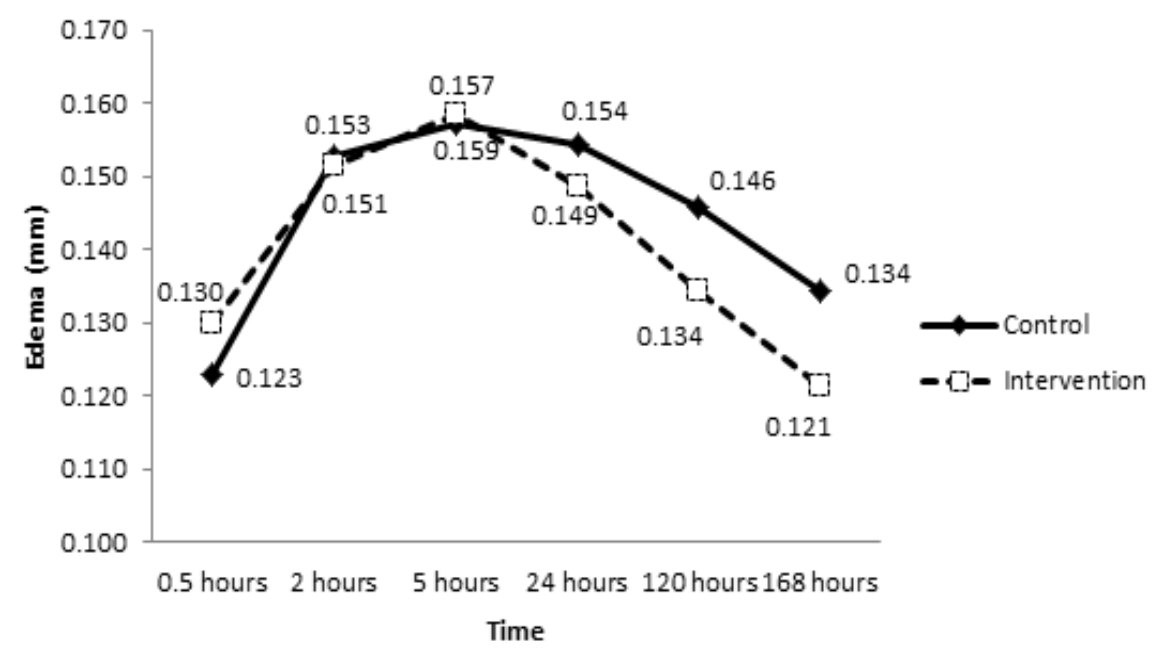

Figure 1 Comparison of the Thickness of Edema and Time of Observation between Two Groups: Control and Intervention 
between the control and intervention animal models, and the statistical analysis showed the $\mathrm{p}$-value of the intervention group was $0.019(\mathrm{p}<0.05)$. This result indicated that there was a difference between the control group and intervention group during the observation time, and this happened as the effect of applying the herbal mixture onto the intervention group.

\section{Discussion}

In this study, it wasfound that the herbal mixture could significantly prevent the deterioration of injury and decrease the edema formation in rabbit ears. The results suggested that the herbal mixture of ginger, garlic and coconut oil (kletik oil) had active medical ingredients for activating the blood and removing stasis, hence promoting wound healing. Wound healing of the skin can be divided into 3 phases: inflammatory, proliferative and remodeling phase. The inflammatory phase is the initial phase which ranges from 2-6 days. The observation time started at 0.5 hours up to 5 hours, and showed there was no difference in the thickness of edema between the two groups. Beginning from 24 hours until 168 hours, the difference of thickness of edema was shown between the two groups. Meanwhile, the intervention group showed less edema formation. This explained that the mixture of garlic, ginger and coconut oil (kletik oil) had anti-inflammatory properties that could decrease the inflammation reaction hence decreased edema formation. A previous study suggested that other types of herbal mixtures had also proved to decrease the thickness of inflammatory reaction (edema) on soft tissue injury.11 Furthermore, other herbal mixtures (four China's Tibetan medical herbs, including Lamiophlomis rotata, Oxytropis falcate Bunge, Curcuma longa Linn, and Myricaria bracteata.) applied onto test rabbits showed the onset of action for these herbal mixtures was on the 24 hours as well. Moreover, the effect on inhibition of TNF- $\alpha$ production by the ginger extract was earlier reported because ginger is known to have a moderate effect on osteoarthritis in vivo, and it also has a promising effect of ginger extract in experimental arthritis in rats. Additionally, another previous study stated that, ginger extract EV77/15 is as effective an anti-inflammatory agent as betamethasone in this in vitro cell model of cultured fibroblastlike synoviocytes. ${ }^{10,11}$

In this study, it was found that ginger and its main components, gingerols, can inhibit synthesis of several pro-inflammatory cytokines including IL-1, TNF- $\alpha$ and IL-8 along with inhibiting prostaglandin (PG) and leukotriene (LT) synthesis enzymes. Furthermore, ginger also exerted effect on several genes encoding cytokines, chemokines and the inducible enzyme cyclo-oxygenase- 2 (COX-2). ${ }^{6}$

Kletik oil (coconut oil) is rich in fatty acids of medium chain length (6-12 C) of which the major fatty acid is lauric-acid (12 C). Fatty acids are bioactive molecules, which have been proved to modulate cellular proliferation, cell signaling and growth factor activities. Kletik oil contains higher amounts of antioxidant polyphones, catechins, ferulic acid, p-coumaric acid, caffeic acid, and unidentified phenolic acid and unidentified flavonoids. Hence, the cumulative effect of these compounds may fasten and prove to be beneficial to the wound healing process which was able to decrease the swelling in this study. ${ }^{3}$

Lastly, garlic that contains a reactive compound (allicin), inhibited the migration of neutrophilic granulocytes into epithelia, which was a crucial process during inflammation and also inhibited TNF $\alpha$-dependent proinflammatory cytokines. Furthermore, allicin also acted on T-cell lymphocytes by inhibition of the SDF1 $\alpha$-chemokine-induced chemotaxis and this effect was correlated with an impaired dynamic of the actin-cytoskeleton. ${ }^{5}$

In conclusion, the usage of herbal mixture consisting of ginger, garlic, and coconut oil (kletik oil) somehow possesses antiinflammatory properties which can help the healing process in soft tissue injury.

This was an animal model experiment, which could differ when applied onto human's soft tissue injury. It is important to perform further studies on humans.

\section{References}

1. Kaur J, Kaur S, Mahajan A. Herbal medicines: possible risks and benefits. AJPCT. 2013;2:226-39.

2. Fraenkel L, Bogardus ST, Concato J, Wittink DR. Treatment options in knee osteoarthritis ( The patient's perspective ). Arch Intern Med. 2004;164:1299-304.

3. Rajamohan T, Nevin KG. Effect of topical application of virgin coconut oil on skin components and antioxidant status during dermal wound healing in young rats. Skin Pharmacol Physiol. 2010;23:290-7.

4. Zar C, Das S. Potential effect of herbs on diabetic hypertension: alternative 
medicine treatment modalities. La Clinica terapeutica. 2013;164(6):529-35.

5. Borlinghaus J, Albrecht F, Gruhlke $\mathrm{MCH}$, Nwachukwu ID, Slusarenko AJ. Allicin : chemical and biological properties. Molecules. 2014;19:12591-618.

6. Mahluji S, Ostadrahimi A, Mobasseri M, Ebrahimzade Attari V, Payahoo L. Antiinflammatory effects of zingiber officinale in type 2 diabetic patients. Adv Pharm Bull. 2013;3(2):273-6.

7. Mescher AL., editor, Skin,. 2010 Junqueira basic histology text and atlas. 12th ed. Bloomington: McGraw-Hill Education; 2010. p. 316-23.

8. Kumar V, Abbas AK, Fausto N, Aster JC. General Pathology. In: Abbas AK, editor. 2010 Robbins and Cotran: Pathologic basis of disease. 8th ed. Philadelphia: Elsevier-
Health Science Division; 2010. p. 3-43.

9. Nieman DC, Shanely RA, Luo B, Dew D, Meaney MP, Sha W, et al. A commercialized dietary supplement alleviates joint pain in community adults: a double-blind, placebo-controlled community trial. Nutr J. 2013;12(1):1-9.

10. Ribel-Madsen $S$, Bartels EM, Stockmarr A, Borgwardt A, Cornett C, DanneskioldSamsoe B, et al. A synoviocyte model for osteoarthritis and rheumatoid arthritis: response to ibuprofen, betamethasone, and ginger extract-a cross-sectional in vitro study. Arthritis. 2012;2012:1-9.

11. Wang YZ, Guo CY, Zhong HG, WN. Z, Wang DL, Wang $X$, et al. In vivo effects of pain relieving plaster on closed soft tissue injury in rabbit ears. BMC Complement Altern Med. 2008;8:1-7. 